\title{
AKTIVITAS HARIAN ORANGUTAN KALIMANTAN (Pongo pygmaeus) PASCA PELEPASLIARAN DI HUTAN LINDUNG GUNUNG TARAK, KALIMANTAN BARAT
}

\section{(DAILY ACTIVITIES OF ORANGUTAN KALIMANTAN (Pongo pygmaeus) POST-RELEASE IN GUNUNG TARAK NATURE RESERVE, WEST KALIMANTAN)}

\author{
Christina E. M. Hutabarat, Ahmad Sjarmidi, Dian Rosleine \\ Sekolah Ilmu Teknologi Hayati, Institut Teknologi Bandung, Ganesa 10, Bandung \\ E-mail: christina.hutabarat16@gmail.com
}

(diterima Maret 2018, direvisi Agustus 2018, disetujui November 2018)

\begin{abstract}
ABSTRAK
Orangutan kalimantan (Pongo pygmaeus) pasca rehabilitasi membutuhkan waktu untuk bisa bertahan hidup di habitat aslinya setelah dilepasliarkan. Penelitian ini bertujuan untuk melihat aktivitas harian orangutan pasca rehabilitasi. Penelitian ini dilakukan di hutan Gunung Tarak, Kalimantan Barat. Pengamatan perilaku orangutan dilakukan dengan metode focal animal sampling dan instantaneous sampling per dua menit. Pengamatan dilakukan terhadap dua individu orangutan Susi dan Peni yang sudah dilepasliarkan setelah melewati masa rehabilitasi. Ada lima aktivitas harian dari dua orangutan pasca rehabilitasi yang diamati yaitu perilaku makan Susi 54\% dan Peni 52\%, istirahat Susi dan Peni sama yaitu 17\%, traveling Susi dan Peni sama yaitu 9\%, interaksi dengan manusia yaitu Susi 1,3\% dan Peni $0,6 \%$, aktivitas membangun sarang Susi dan Peni sama yaitu 1\%. Berdasarkan data aktivitas harian Susi dan Peni maka dapat disimpulkan bahwa aktivitas harian Susi dan Peni tidak jauh berbeda meskipun berbeda masa pelepasliaran dan orangutan pasca pelepasliaran membutuhkan kurang lebih dua atau tiga tahun untuk bisa hidup mandiri dan bertahan hidup di habitat alaminya.
\end{abstract}

Kata kunci: Program pelepasliaran, Gunung Tarak, pasca rehabilitasi

\begin{abstract}
The Bornean orangutan (Pongo pygmaeus) ex-rehabilitation takes time to bertahan hidup in their natural habitat after being released. This study aims to see the daily activities of orangutans after rehabilitation. The research was conducted in the forest of Gunung Tarak Nature Reserve, West Kalimantan. Observation of orangutan behavior was done by focal animal and instantaneous sampling method every two minutes. Observations were made of two individuals of Susi and Peni orangutans who had been released after the rehabilitation period. There were five daily activities of two ex-rehabilitation orangutans observed: Feeding activity Susi 54\% and Peni 52\%, Resting activity both same Susi and Peni, 17\%, Traveling activity Susi and Peni, 9\% human interaction with Susi 1.3\% and 0.6\% peni, the activity of building Susi and Peni's nest is $1 \%$. Based on Susi and Peni's daily activity data, it can be concluded that the daily activities of Susi and Peni are not much different even though different release periods and post-release orangutans require approximately two or three years to be able to live independently and bertahan hidup in their natural habitat.
\end{abstract}

Keywords: Release program, Gunung Tarak, Ex-rehabilitation

\section{PENDAHULUAN}

Orangutan sangat berpengaruh terhadap kelestarian ekosistem dan kestabilan hutan. Menurut Roberge \& Angelstam (2004), keberadaan 1-10 orangutan di habitatnya pada tiap kilometer perseginya, dapat mendatangkan paling tidak lima jenis burung rangkong, menumbuhkan 50 jenis pohon buah -buahan, dan 15 jenis pohon lainnya (regenerasi tumbuhan hutan). Hewan pemakan buah (frugivor) ini membuang biji-biji buah yang dimakan yang kemudian tumbuh menjadi tumbuhan baru, misalnya biji durian hutan, rambutan hutan, langsat, dan lain sebagainya (Santosa dkk. 2010). Dengan begitu orangutan disebut sebagai salah satu species payung (umbrella species) (Noss dkk. 2002).

Orangutan diklasifikasikan sebagai hewan yang kritis (IUCN, 2006). Dalam penelitiannya, Primack dkk. 

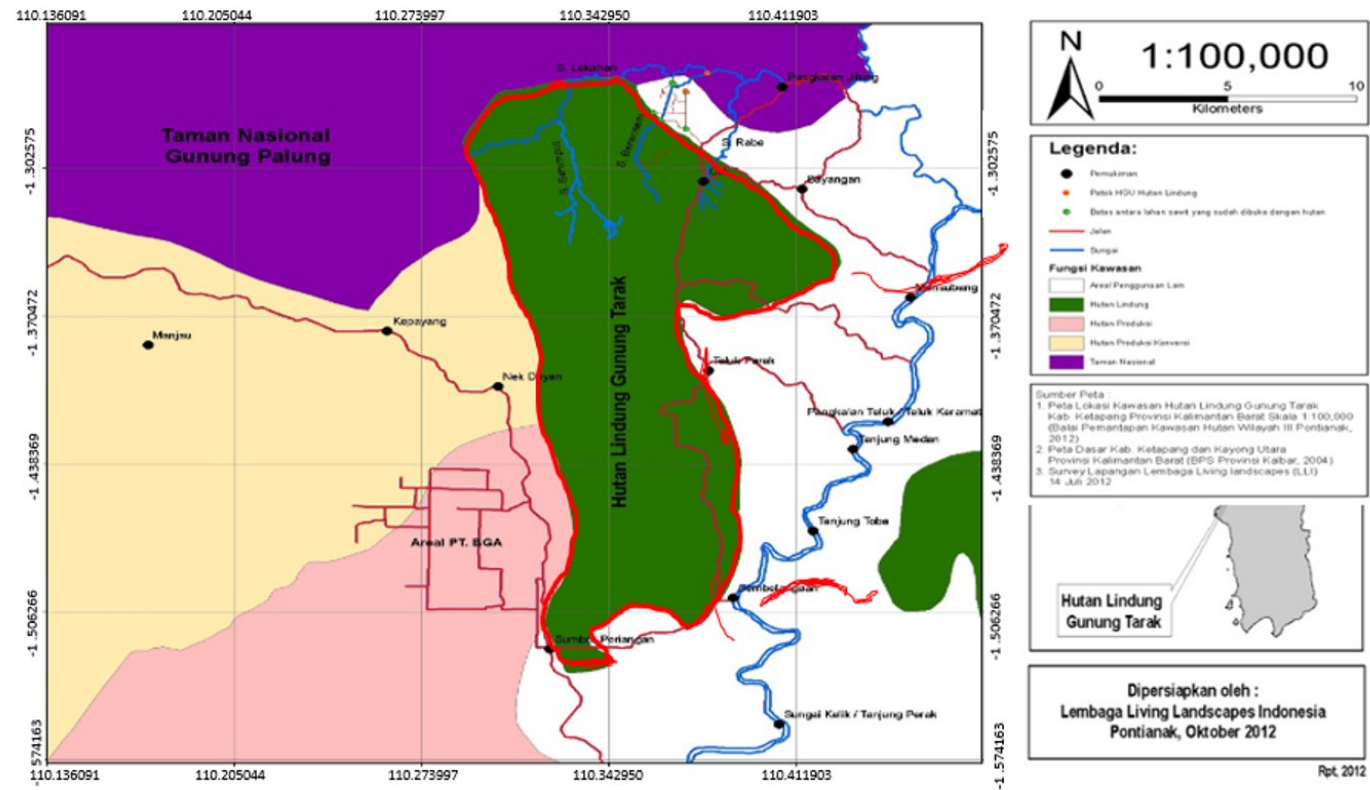

Gambar 1. Hutan lindung Gunung Tarak

menyatakan bahwa pada tahun 1993, diperkirakan jumlah orangutan Indonesia dan Malaysia telah menurun $30-50 \%$ dalam kurun waktu 10 tahun terakhir, sementara habitatnya telah menyusut sebanyak $80 \%$ dalam kurun waktu 20 tahun terakhir. Keberlangsungan hidup orangutan terancam karena adanya degradasi habitat (Meijaard dkk. 2001). Hilangnya habitat akibat konversi hutan menjadi perkebunan, illegal logging dan fragmentasi habitat menyebabkan ruang gerak orangutan semakin sempit. Hal tersebut menyebabkan orangutan memasuki kawasan perbatasan hutan dan perkampungan.

Hutan Lindung Gunung Tarak, Kalimantan Barat menjadi salah satu habitat yang dihuni oleh orangutan yang sudah dilepasliarkan kembali (Komunikasi pribadi dengan Gail, 2017). Fenomena yang terjadi ialah orangutan yang sudah dilepasliarkan membutuhkan waktu yang lama untuk liar di hutan meskipun sebelumnya sudah mengikuti rehabilitasi dan sekolah alam. Hal itu terbukti dari lamanya orangutan dipantau dan adanya orangutan yang mendekati lahan masyarakat setelah pelepasliaran (Komunikasi pribadi dengan Gail, 2017). Salah satu indikator berhasilnya pelepasliaran orangutan dilihat dari hasil monitoring aktivitas harian secara berkala. Hasil monitoring dijadikan sebagai acuan dalam menentukan berapa lama waktu yang dibutuhkan untuk melakukan monitoring terhadap orangutan yang sudah dilepasliarkan kembali. Perilaku harian yang dijadikan indikator berupa perilaku makan, bergerak, membuat sarang, istirahat dan sosial. Oleh karena itu, dengan penelitian ini dapat diketahui aktivitas harian orangutan pasca rehabilitasi setelah dilepasliarkan kembali.

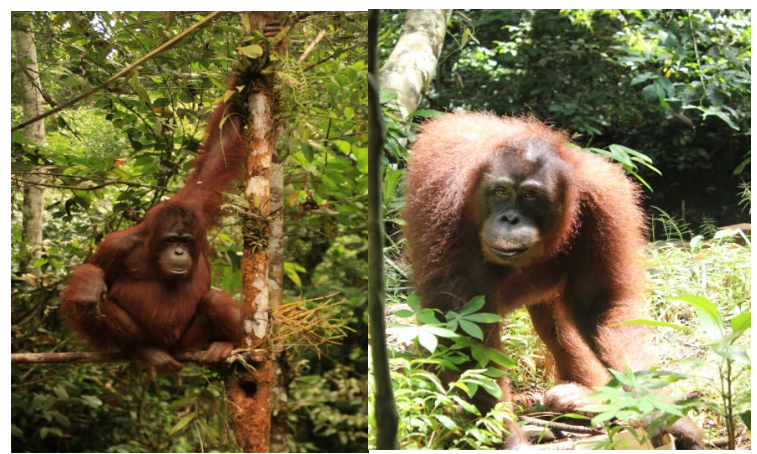

Gambar 2. Objek Penelitian: Susi (kiri); Peni (kanan). (Dokumentasi pribadi, 2017) 
Tabel 1. Jumlah waktu pengamatan Susi dan Peni

\begin{tabular}{cllllll}
\hline No & $\begin{array}{l}\text { Nama } \\
\text { Orangutan }\end{array}$ & $\begin{array}{l}\text { Jenis } \\
\text { Kelamin }\end{array}$ & $\begin{array}{l}\text { Usia saat } \\
\text { disita }\end{array}$ & Rehabilitasi & Pelepasliaran & $\begin{array}{l}\text { Jumlah waktu } \\
\text { pengamatan* }\end{array}$ \\
\hline 1 & Susi & Betina & 3 tahun & 2010 & 2013 dan 3 Okt 2014 & 59,6 jam \\
2 & Peni & Betina & 5 tahun & 2011 & 20 Mei 2016 & 225,3 jam \\
\hline
\end{tabular}

*(selama pengamatan langsung/bulan)

Pengamatan perilaku orangutan dilakukan dengan metode focal animal sampling dan instantaneous sampling. Focal animal sampling ialah pengamatan orangutan sepanjang hari mulai dari bangun sampai tidur (nest to nest). Instatenous sampling ialah metode pencatatan data perilaku dalam interval waktu dua menit (Altman, 1974). Peni sudah dilepasliarkan kurang lebih 3 tahun sedangkan Susi 2 tahun. Tahun 2013 Peni sudah dilepasliarkan tetapi tidak dapat bertahan hidup di hutan, sehingga Peni dibawa kembali ke pusat rehabilitasi dan dilepasliarkan kembali tahun 2014. Orangutan pasca pelepasliaran dipantau sejak dilepasliarkan sampai bisa beradaptasi di hutan.

1. Perilaku Makan

Pada orangutan aktivitas makan (feeding) merupakan aktivitas yang menggunakan waktu lebih banyak dari aktivitas harian lainnya. Perilaku anak orangutan mengalami perubahan secara signifikan pada saat mencapai umur enam tahun atau pada saat disapih. Perubahan perilaku tersebut seperti berkurangnya waktu istirahat diiringi dengan bertambahnya waktu makan (van Schaik dkk. 2004).

2. Perilaku istirahat

Perilaku istirahat dilakukan pada saat individu tidak melakukan aktivitas yang menyebabkan perpindahan posisi. Orangutan memilih tempat yang nyaman untuk beristirahat misalnya seperti sarang, cabang, dan ranting pohon (MacKinnon 1974).

3. Perilaku bergerak

Orangutan merupakan primata yang aktif menjelajah dengan cara berpindah dari satu pohon ke pohon yang lain menggunakan liana, cabang atau ranting. Sebagian besar primata menjelalah hutan untuk mencari pakan (Milton dkk. 1976).

4. Perilaku sosial

Perilaku sosial di dalam aktivitas harian orangutan ditemukan pada hubungan ibu dan anak, sesama anak-anak, dan pada orangutan dewasa jantan dan betina menjelang musim kawin (Singleton 2000).

5. Membangun sarang

Kemampuan membuat sarang menjadi faktor penting dalam menentukan kesintasan orangutan di habitatnya. Menurut MacKinnon (1974) waktu untuk membuat sarang dapat dipengaruhi oleh faktor cuaca, jarak sarang dari pohon, dan rasa lapar dari tiap individu untuk memenuhi kebutuhannya.

Data yang didapat selama di lapangan disusun dalam Microsoft Excel. Dalam menganalisis data digunakan statistik non-parametrik. Analisis data dilakukan dengan menggunakan program SPSS 16.0 for Windows. Uji statistik non parametrik yang digunakan adalah Mann-Whitney Test untuk menguji data dengan dua sampel bebas. 


\section{HASIL DAN PEMBAHASAN}

\section{Etogram Pengamatan Susi dan Peni}

Orangutan melakukan aktivitas harian mulai dari bangun sampai tidur kembali. Apabila musim buah maka orangutan akan menggunakan waktu yang lama untuk makan dan berpindah tempat, sehingga waktu istirahat berkurang. Aktivitas harian orangutan pasca rehabilitasi diamati selama 33 hari di Hutan Lindung Gunung Tarak. Jumlah total pengamatan yang dilakukan terhadap Susi 59,6 jam dan Peni 225,3 jam (Tabel 1). Dari 36 perilaku yang ada di etogram rujukan, terdapat 30 perilaku yang dilakukan Susi dan Peni. Perbedaannya terdapat pada perilaku sosial antara orangutan (social behavior) dan interaksi antara orangutan dengan manusia (human interaction). Ada perilaku berbeda yang dilakukan oleh Peni dan Susi pada saat makan yaitu dengan memakan sampah dan sejenisnya.

Tabel 2. Persentase durasi perilaku harian Susi dan Peni

\begin{tabular}{clcc}
\hline & \multirow{2}{*}{ No } & Perilaku Harian & \multicolumn{2}{c}{ \% Durasi Harian } \\
& & Susi & Peni \\
\hline 1 & Makan & 53,71 & 51,35 \\
2 & Istirahat & 16,4 & 16,52 \\
3 & Berpindah tempat & 9,32 & 8,78 \\
4 & Membangun sarang & 1,1 & 1,19 \\
5 & Perilaku Sosial & 2,85 & 5,18 \\
\hline
\end{tabular}

Berdasarkan pengamatan yang dilakukan terhadap Susi dan Peni terdapat persentase data perilaku harian yang tidak jauh berbeda, misalnya dalam hal makan, berpindah tempat, istirahat, dan membangun sarang. Letak perbedaan perilaku harian Susi dan Peni terdapat pada perilaku sosial yaitu Susi lebih agresif, misalnya Susi mencuri makanan Peni meski kadang Susi dan Peni terlihat bermain bersama. Perilaku lain ialah interaksi dengan manusia, sehingga pada pengamatan terlihat bahwa Susi dan Peni sudah terbiasa berdekatan dengan manusia.

Orangutan pasca pelepasliaran memiliki proses yang berbeda satu sama lain dalam hal survival di hutan. Kehidupan selama di rehabilitasi dan sekolah alam menjadi faktor pendukung yang sangat penting untuk melihat keberhasilan mereka untuk mandiri. Menurut Rodman (1979), perilaku harian orangutan yang paling banyak didominasi ialah perilaku makan, istirahat, bermain, berjalan-jalan di antara pepohonan dengan membuat sarang untuk beberapa waktu. Berdasarkan pengamatan di lapangan, secara keseluruhan perilaku harian Susi dan Peni tidak jauh berbeda secara persentase meskipun mereka dilepasliarkan di tahun yang berbeda (Tabel 2).

Persentase dari kelima aktivitas utama yang dijadikan kriteria kesuksesan seperti makan, istirahat, bergerak, membangun sarang dan sosial tidak jauh berbeda dari total keseluruhan aktivitas harian orangutan. Susi menggunakan waktu lebih banyak untuk makan daripada Peni. Terlihat bahwa Susi lebih aktif dalam bergerak dan mencari pakan. Susi dan Peni menggunakan proporsi waktu yang sama untuk beristirahat.

Aktivitas makan ialah waktu yang dipakai orangutan untuk menggapai, mengolah, mengekstraksi, memegangmegang, mengunyah, dan menelan makanan. Susi dan Peni menggali tanah dengan merobek -robek bagian luarnya apabila mereka memakan serangga atau rayap di tanah. Pada saat tidak musim buah, orangutan menghabiskan waktunya untuk berjalan dan makan hanya sedikit. Terdapat perbedaan pola 
aktivitas harian orangutan sumatera pada saat hari kering dan hari basah. Pada saat hari kering waktunya lebih banyak dihabiskan untuk beristirahat daripada aktivitas makan dan berjalan (MacKinnon, 1974).

Berdasarkan data signifikansi yang diuji menggunakan data harian orangutan terdapat perilaku harian antara Susi dan Peni yang berbeda nyata. Perilaku (traveling) Peni nyata lebih rendah dari Susi $(\alpha=0.05)$. Pada hasil statistik nilai rata-rata/median waktu yang digunakan Susi (25) dan Peni (19) berbeda jauh. Nilai signifikansi $p$ ialah 0.004. Susi lebih lama menggunakan waktu hariannya untuk berpindah tempat dibanding Peni sehingga dapat dikatakan Susi lebih aktif daripada Peni dalam berpindah tempat.

Perilaku makan Susi dan Peni berbeda nyata. Susi lebih banyak makan daripada Peni disebabkan aktivitas bergerak Susi yang lebih banyak dari Peni. Semakin jauh jarak lokomosi orangutan maka semakin banyak energi yang dibutuhkan untuk bergerak dan berpindah. Perilaku ketiga yang berbeda nyata ialah perilaku sosial, Peni lebih sosial dibandingkan Susi. Hal tersebut menunjukkan bahwa kebergantungan Peni lebih tinggi terhadap orangutan lain.

Distribusi orangutan dipengaruhi oleh sebaran habitat yang memiliki ketersedian makanan sepanjang tahun dan apabila lokasi tersebut sudah tidak produktif lagi, maka orangutan akan terus bermigrasi ke daerah lain di mana habitat tersebut menyimpan ketersedian makanan yang lebih baik dari habitat sebelumnya (Buij dkk, 2002; Susanto, 2006). Gunung tarak termasuk di dalam kawasan hutan yang memiliki kekayaan sumber daya alam. Termasuk di dalam ketersediaan pakan orangutan seperti buah, daun, liana, dll. Susi dan Peni merupakan orangutan pasca rehabilitasi yang cepat mengenali pakan ketika dilepasliarkan.

Susi dan Peni memiliki home range tersendiri dengan persediaan pakan yang cukup untuk memenuhi kebutuhan energi setiap harinya. Apabila mengalami kelangkaan maka orangutan tersebut akan berkeliling mencari pakan. Banyak jenis pakan yang dimakan oleh Susi dan Peni seperti buah, daun, rayap, kulit batang, liana, rotan, dan lain -lain. Susi dan Peni memilih pakan yang tidak jauh berbeda setiap harinya meskipun daerah jelajah (home range) mereka berbeda. Tanaman Jambu monyet (Bellucia pentamera) banyak ditemukan di Gunung Tarak.

Susi dan Peni dapat dinyatakan terlalu muda untuk dilepasliarkan sehingga sampai sekarang ini kedua orangutan tersebut masih dimonitor setiap hari. Perbedaan survival Susi dan Peni tampak dari lamanya mereka untuk beradaptasi dan menjadi liar. Orangutan lainnya yang terdapat di Gunung Tarak ialah Helen dan Prima (Komunikasi pribadi dengan Gail, 2017) sudah mampu mandiri setelah dimonitor selama kurang lebih dua tahun. Kesulitan menjadi liar bagi orangutan pasca rehabilitasi menunjukkan bahwa perlu dilakukan upaya yang lebih detail akan persiapan orangutan selama berada di pusat rehabilitasi dan sekolah alam, misalnya dengan membuat satu standar bahwa orangutan tersebut dapat makan, istirahat dan traveling sesuai dengan standar yang dibuat untuk orangutan pasca rehabilitasi.

\section{Tingkat Keberhasilan Pelepasliaran}

Berdasarkan hasil pengamatan yang dilakukan di lapangan orangutan yang sudah dilepasliarkan kembali tidak mampu 
beradaptasi di lingkungannya yang baru dalam waktu cepat. Proses adaptasi orangutan yang satu dengan yang lainnya berbeda. Orangutan dapat beradaptasi dengan cepat dan lambat tergantung bagaimana kesiapan mereka sebelum dilepasliarkan. Pada tabel berikut ini ditunjukkan bagaimana aktivitas harian Susi dan Peni setelah dilepasliarkan di Gunung Tarak. Apabila disesuaikan dengan standar yang sudah dilakukan maka dapat dilihat bahwa Susi dan Peni belum memasuki tahap berhasil untuk liar. Keseluruhan data Susi dan Peni menunjukkan bahwa sebagian besar waktu mereka digunakan untuk makan dan istirahat. Apabila dibandingkan dengan standar liar maka dapat disimpulkan bahwa Susi dan Peni belum berhasil untuk hidup liar.

Kemudian perbedaan lainnya dapat dilihat dari data perilaku sosial di mana Susi dan Peni memiliki hubungan sosial sesama orangutan yang cukup tinggi. Hal tersebut menunjukkan bahwa keberadaan orangutan terlalu lama di pusat rehabilitasi dan sekolah alam mempengaruhi hubungan sosial satu sama lain bahkan setelah dilepasliarkan sekalipun. Orangutan pasca rehabilitasi menghabiskan aktivitas hariannya dengan makan yaitu 56\%. Waktu yang cukup lama digunakan orangutan pasca rehabilitasi dengan mencari dan mengonsumsi pakan.

Apabila dibandingkan maka menurut Galdikas (1978) orangutan liar menggunakan $60,1 \%$ waktunya untuk makan, meskipun perbedaannya tidak begitu jauh. Menurut beberapa penelitian yang dilakukan di Kalimantan dan Sumatera, orangutan pasca rehabilitasi dapat dinyatakan liar apabila sudah mencapai standar tersebut. Begitu juga dengan aktivitas lainnya seperti membangun sarang $1,5 \%$, bergerak $18,7 \%$, istirahat $18,2 \%$, perilaku sosial $1,3 \%$, bersuara $0,1 \%$, seks $0,1 \%$.

Kesuksesan pelepasliaran orangutan tampak dari perilaku harian yang mandiri ketika sudah dilepasliarkan. Menurut Galdikas (1978), perilaku orangutan liar dapat diketahui dari perilaku makan, berpindah tempat, istirahat, membangun sarang, perilaku sosial, bersuara, dan juga seksual. Penelitian yang dilakukan di Sumatera menunjukkan bahwa pada umumnya pola aktivitas harian orangutan dibedakan menjadi dua. Aktivitas di pagi hari, dua jam sampai tiga jam setelah orangutan meninggalkan sarang tempat tidurnya dan aktivitas sore hari sekitar pukul tiga sore. Aktivitas makan lebih banyak dilakukan di pagi hari. Aktivitas berjalan lebih banyak dilakukan pada sore hari dan aktivitas beristirahat lebih banyak dihabiskan pada tengah hari (Rijksen, 1978). Dari ketiga aktivitas harian ini, aktivitas yang paling mendominasi adalah aktivitas makan 45,9 \% sedangkan aktivitas istirahat sebesar 39,2 \% (Rodman, 1979).

Aktivitas harian orangutan didukung oleh habitat alami yang menyediakan cukup pakan dan menjadi habitat yang aman dari predator. Galdikas (1978) menyimpulkan standar kesuksesan orangutan liar berdasarkan

Tabel 3. Standar perilaku kesuksesan orangutan liar (Galdikas, 1978)

\begin{tabular}{|c|c|c|}
\hline No & $\begin{array}{l}\text { Perilaku } \\
\text { Standar }\end{array}$ & $\begin{array}{c}\text { Persentase Standar } \\
\text { (Orangutan Liar) }\end{array}$ \\
\hline 1 & Makan & $60,1 \%$ \\
\hline 2 & Bergerak & $18,7 \%$ \\
\hline 3 & Istirahat & $18,2 \%$ \\
\hline 4 & $\begin{array}{l}\text { Membangun } \\
\text { sarang }\end{array}$ & $1,5 \%$ \\
\hline 5 & $\begin{array}{l}\text { Perilaku } \\
\text { sosial }\end{array}$ & $1,3 \%$ \\
\hline 6 & Bersuara & $0,1 \%$ \\
\hline \multirow[t]{2}{*}{7} & Seks & $0,1 \%$ \\
\hline & Total & $100 \%$ \\
\hline
\end{tabular}


pengamatannya terhadap orangutan kalimantan (Tabel 3). Hal tersebut menunjukkan bahwa rata-rata orangutan liar menggunakan waktu yang relatif lebih besar untuk makan, istirahat, dan berpindah tempat. Berdasarkan standar kesuksesan orangutan liar menurut Galdikas (1978) menunjukkan bahwa orangutan harus mampu mencapai titik tersebut untuk mampu dikatakan liar dan mandiri dalam habitat aslinya. Galdikas (1987) melakukan penelitian terhadap orangutan liar di daerah Kalimantan, meskipun sebenarnya dibutuhkan waktu yang lebih lama bagi orangutan pasca rehabilitasi untuk menjadi mandiri seperti orangutan liar.

\section{KESIMPULAN}

Perilaku harian Susi dan Peni diamati menggunakan etogram standar yang dipakai di Gunung Tarak, Kalimantan Barat. Aktivitas harian Susi dan Peni tidak menunjukkan perbedaan yang signifikan meskipun mereka tidak dilepasliarkan dalam waktu yang sama. Susi dan Peni menghabiskan waktu paling lama untuk makan $(53,71 \%, 51,35 \%)$, istirahat $(16,4 \%, 16,52 \%)$, berpindah tempat $(9,32 \%$, $8,78 \%)$, interaksi sosial $(2,85 \%, 5,18 \%)$ dan membangun sarang $(1,1 \%, 1,19 \%)$.

\section{UCAPAN TERIMA KASIH}

Kami mengucapkan terimakasih kepada International Animal Rescue (IAR), Ketapang, Kalimantan Barat yang sudah memberikan kesempatan sehingga penulis dapat melaksanakan penelitian di Hutan Lindung Gunung Tarak. Penulis juga mengucapkan terimakasih kepada Ibu Karmele, Ibu Gail Campbell, drh Adi, Bang Argitoe dan seluruh tim Gunung Tarak. Terkhusus terimakasih kepada Institut Teknologi Bandung yang sudah memberikan saya kesempatan untuk dapat melakukan penelitian ini.

\section{DAFTAR PUSTAKA}

Altman., J. (1974): Observational Study of Behavior: Sampling Methods. All Laboratory of Animal Behavior, University of Chicago, Chicago.

Buij, R., Wich, S.A., Lubis, A.H., \& Sterck, E.H.M. (2002). Seasonal movements in the Sumatran orangutan (Pongo pygmaeus abelii) and consequences for conservation. Biol. Cons. 107: 83-7

Fakhrurradhi. (1998). Komposisi Pakan Orangutan Sumatera (Pongo pygmaeus abelii, Lesson 1827) di Suaq Balimbing. Taman Nasional Gunung Leuser. Skripsi Sekolah Tinggi Ilmu Kehutanan Banda Aceh

Galdikas, B.M.F. (1978). Orangutan adaptation at Tanjung Puting reserve, Central Borneo, Ph.D, Thesis, University of California, Los Angeles, xxxvii +361 hlm

IUCN (2006). IUCN Red List of Threatened Species. IUCN, Gland, Switzerland and Cambridge, United Kingdom. Available from the IUCN Publications Services Unit or $\underline{w w w . r e d l i s t . o r g}$

Mac Kinnon., J. R. (1974). The Ape Within Us, Holt, Rinehard and Wisnton, New York.

Meijaard, E., H.D. Rijksen \& S.N. Kartikasari (2001). Diambang Kepunahan! Kondisi Orangutan Liar di Awal Abad ke-21, Cetakan Pertama. The Gibbon Foundation Indonesia, Jakarta, xxxi + $393 \mathrm{hlm}$

Milton, K dan M. L. May. (1976): Body weight, diet and home range area in 
primates, Nature, 259: 459--462.

Noss RF, Caroll C, Vance-Borland K, \& Wuerthner G. (2002). A multicriteria assessment of the irreplaceability and vulnerability of sites in the greater Yellowstone ecosystem. Conservation Biology 16:895-908. DOI:10.1046/ j.1523-1739.2002.01405.x.

Primack BR, Supriatna J, Indrawan M, \& Kramadibrata P. (1998). Biologi Konservasi. Yayasan Obor Indonesia. Jakarta

Roberge J.M \& Angelstam P. (2004). Usefulness of the umbrella species concept as a conservation tool. Conservation Biology18:76-85. DOI: 10.1111/j.1523-1739.2004.00450.X.

Rodman, P. S. (1979). Individual Activity Patterns and the Solitary Nature of Orangutan. The Great Apes. The Benjamin Gemming Publishing Company: California

Santosa Y, Fauzan PA, \& Mustari AH. (2010). Estimation of re-introduced sumatran orangutan's (Pongo pygmaeus abelii) nest based on nest size and colour in Bukit Tigapuluh National Park Sumatera. Media Konservasi Edisi Khusus:1-5.

Singleton, I. (2000): Ranging behaviour and seasonal movements of Sumatran orangutans (Pongo pygmaeus abelii) in swamp forests. Ph.D. Thesis. The Durrell Institute of Conservation and Ecology, University of Kent, Canterbury: $x i+196 \mathrm{hlm}$.

Susanto, T.W. (2006). Pemanfaatan ruang aktivitas antar individu orangutan (Pongo pygmaeus wurmbii, Tiedemann 1808) jantan di Stasiun Penelitian Orangutan Tuanan, Kalimantan Tengah. Skripsi. Fakultas Biologi Universitas Nasional. Jakarta.

van Schaik., C. P., Husson S., Meijaard E., Singleton I., Wich S.A. (2004): The status of the orangutan in Indonesia 2003. Orangutan population and habitat viability assessment: Final report tothe Orangutan Foundation: Jakarta, Indonesia. 